\title{
Do multiple fires interact to affect vegetation structure in temperate eucalypt forests?
}

\author{
Angie Haslem,,${ }^{1,8}$ Steve W. J. Leonard, ${ }^{1}$ Matthew J. Bruce, ${ }^{2}$ Fiona Christie, ${ }^{3}$ Greg J. Holland, 4,6 \\ Luke T. Kelly, ${ }^{5}$ Josephine MacHunter, ${ }^{2}$ Andrew F. Bennett, ${ }^{4,6,7}$ Michael F. Clarke, ${ }^{1}$ and Alan York ${ }^{3}$ \\ ${ }^{1}$ Department of Ecology, Environment and Evolution, La Trobe University, Bundoora, Victoria 3086 Australia \\ ${ }^{2}$ Department of Environment, Land, Water and Planning, Arthur Rylah Institute for Environmental Research, 123 Brown Street, \\ Heidelberg, Victoria 3084 Australia \\ ${ }^{3}$ School of Ecosystem and Forest Sciences, University of Melbourne, Creswick, Victoria 3363 Australia \\ ${ }^{4}$ School of Life and Environmental Sciences, Deakin University, Burwood, Victoria 3125 Australia \\ ${ }^{5}$ School of BioSciences, ARC Centre of Excellence for Environmental Decisions, University of Melbourne, Parkville, \\ Victoria 3052 Australia
}

\begin{abstract}
Fire plays an important role in structuring vegetation in fire-prone regions worldwide. Progress has been made towards documenting the effects of individual fire events and fire regimes on vegetation structure; less is known of how different fire history attributes (e.g., time since fire, fire frequency) interact to affect vegetation. Using the temperate eucalypt foothill forests of southeastern Australia as a case study system, we examine two hypotheses about such interactions: (1) post-fire vegetation succession (e.g., time-since-fire effects) is influenced by other fire regime attributes and (2) the severity of the most recent fire overrides the effect of preceding fires on vegetation structure. Empirical data on vegetation structure were collected from 540 sites distributed across central and eastern Victoria, Australia. Linear mixed models were used to examine these hypotheses and determine the relative influence of fire and environmental attributes on vegetation structure. Fire history measures, particularly time since fire, affected several vegetation attributes including ground and canopy strata; others such as low and sub-canopy vegetation were more strongly influenced by environmental characteristics like rainfall. There was little support for the hypothesis that post-fire succession is influenced by fire history attributes other than time since fire; only canopy regeneration was influenced by another variable (fire type, representing severity). Our capacity to detect an overriding effect of the severity of the most recent fire was limited by a consistently weak effect of preceding fires on vegetation structure. Overall, results suggest the primary way that fire affects vegetation structure in foothill forests is via attributes of the most recent fire, both its severity and time since its occurrence; other attributes of fire regimes (e.g., fire interval, frequency) have less influence. The strong effect of environmental drivers, such as rainfall and topography, on many structural features show that foothill forest vegetation is also influenced by factors outside human control. While fire is amenable to human management, results suggest that at broad scales, structural attributes of these forests are relatively resilient to the effects of current fire regimes. Nonetheless, the potential for more frequent severe fires at short intervals, associated with a changing climate and/or fire management, warrant further consideration.
\end{abstract}

Key words: Australia; eucalypt forest; fire frequency; fire regime; fire severity; habitat change; inter-fire interval; post-fire chronosequence; time since fire; vegetation succession.

\section{INTRODUCTION}

Fire is a key driver of ecosystem change globally (Bowman et al. 2009). One of the strongest and most immediate outcomes of fire is the way it changes vegetation structure, and it is through such effects that fire often has a strong influence on other components of the biota (Hutto

Manuscript received 5 January 2016; revised 9 May 2016; accepted 24 June 2016. Corresponding Editor: B. P. Wilcox.

${ }^{6}$ Present address: Department of Ecology, Environment and Evolution, La Trobe University, Bundoora, Victoria 3086 Australia.

${ }^{7}$ Present address: Department of Environment, Land, Water and Planning, Arthur Rylah Institute for Environmental Research, 123 Brown Street, Heidelberg, Victoria 3084 Australia.

${ }^{8}$ E-mail: a.haslem@latrobe.edu.au
2008, Lindenmayer et al. 2008, Nimmo et al. 2014). For example, changes to vegetation structure after fire alter the availability of important habitat resources for fauna, such as the cover of litter and shrub layers (Fox 1982, Pons and Prodon 1996, Parr et al. 2004, Kelly et al. 2011). Removal of understorey vegetation by fire can also increase predation risk for animals in recently burnt habitats (Catling 1991, Doherty et al. 2015). Not only does understanding of how fire affects vegetation structure provide important insights into fire-fauna relationships, such knowledge forms the basis for predicting the effect of planned fire on fuel distribution and fire risk (Fernandes and Botelho 2003). For both reasons, empirical understanding of the relationship between fire regime attributes and vegetation structure is essential for effective fire management. 
Fire affects vegetation via the attributes of individual fire events, such as fire severity or time since fire; as well as by the sequence of fire events through time, the fire regime (Gill 1975, Gill et al. 2002). For example, the severity of fire events determines the degree to which vegetation structure is altered (Smucker et al. 2005). Following fire, vegetation then undergoes successional changes (Noble and Slatyer 1980), with the strength and temporal span of such time since fire trajectories varying between systems (e.g., Ferran and Vallejo 1992, Lecomte et al. 2006, Capitanio and Carcaillet 2008, Haslem et al. 2011). The length of time between fires (fire interval) can influence the persistence of individual plant species by affecting whether reproductive maturity has been reached at the time of fire (Noble and Slatyer 1980) and cause major and long-lasting change to vegetation structure and composition (Zedler et al. 1983). Other influential factors include the season of a fire event, which can affect post-fire germination and growth (Ashton and Martin 1996), and the fire frequency, which can influence vegetation composition (Kodandapani et al. 2004). While the effect of these factors is influenced by the characteristics of fire in different ecosystems, such as the degree to which fires are stand-replacing, their combined effects result in complex changes to vegetation structure that can persist for many decades (Lecomte et al. 2006).

Fire-vegetation relationships have primarily been considered in relation to the influence of individual fire history attributes (e.g., time since fire, or fire severity, or fire frequency). Less is known about the degree to which different fire history characteristics interact to affect vegetation. Nonetheless, existing understanding of firevegetation relationships suggests plausible hypotheses about such interactions. For example, the effect of fire frequency on vegetation (e.g., Fisher et al. 2009) suggests that post-fire succession may differ between areas with few past fires and those burnt more regularly. Or, the effects of fire severity on vegetation (e.g., Smucker et al. 2005) may override any influence of fire interval. Such interactions between different attributes of fire regimes remain poorly understood, despite having the potential to alter current understanding of both fire--vegetation and fire-fauna relationships.

Vegetation structure is also influenced by environmental variation, such as soil characteristics (Motzkin et al. 1999), topographic features (Parker 1991), and rainfall gradients (Williams et al. 1996). Such environmental drivers produce the natural template of vegetation patterns onto which the effects of disturbances like fire are overlaid. For example, vegetation type and topography are known to influence the occurrence and severity of fire (Beaty and Taylor 2008, Leonard et al. 2014). In systems where fire is actively managed to manipulate fuel loads, an important consideration for managers is the degree to which fire (i.e., management actions) can be expected to influence vegetation structure/fuel characteristics or whether factors outside management control (e.g., environmental gradients) have a greater effect on vegetation/fuel attributes. Fire management will be most effective in systems where vegetation/fuel is strongly influenced by fire events/regimes.

We investigate the strength of interactions between different fire history attributes, and the relative influence of fire and environmental drivers, by using foothill forest vegetation in southeastern Australia as a case study system. Foothill forests are temperate forests that are widespread across Victoria (covering $\sim 7.5$ million hectares) and often occur in close proximity to human settlements. While prescribed burns for fuel reduction are common in foothill forests, understanding of fire-biota relationships remains patchy. Further, understanding of the strength of the effect of fire on vegetation structure, relative to other environmental drivers (e.g., rainfall, topography) in this large study region, is poor. We examine the following questions: (1) What is the relative influence of fire and environmental drivers on vegetation structure in foothill forests?, (2) Is post-fire change in vegetation structure (e.g., time-since-fire effects) influenced by other attributes of fire regimes (e.g., severity, fire frequency, fire interval)?, and (3) Does the severity of the most recent fire alter the effects of preceding fires (e.g., fire frequency, fire interval) on vegetation structure?

\section{Methods \\ Study area}

The study area covers approximately $156,000 \mathrm{~km}^{2}$ of central and eastern Victoria, Australia (Fig. 1). Climatic conditions in the region are temperate, with mean annual rainfall ranging between $\sim 700$ and $1,600 \mathrm{~mm}$, predominantly falling in winter months. Native vegetation in the study region ranges from tall wet forests to shrublands. We focus specifically on vegetation communities collectively termed "foothill forests" that occur on the lower slopes of the Great Dividing Range and Otway Ranges and into East Gippsland. Foothill forests are open eucalypt forests typically dominated by Eucalyptus obliqua, E. radiata, and E. dives. Understory and ground strata vary in density and composition, with common species including a range of sclerophyllous shrubs and perennial grasses (e.g., Poa spp., Tetrarrhena juncea) as well as Pteridium esculentum (Conn 1993). These forests exhibit both broad-scale variation (e.g., E. sieberi is increasingly common in the east), as well as finer-scale gradients related to topographic variation. Slopes and ridges support drier, more open vegetation whereas moister gullies comprise denser vegetation, including the canopy species E. globulus, and a diversity of broadleaved shrubs (e.g., Bedfordia arborescens, Pomaderris aspera, Coprosma quadrifida, Olearia spp.) and tree ferns (Dicksonia antarctica, Cyathea spp.).

The region has been heavily cleared for human settlements and land uses, and most forest vegetation has experienced timber harvesting, either clear-felling or selective logging (Lutze et al. 1999). Foothill forests have a long 


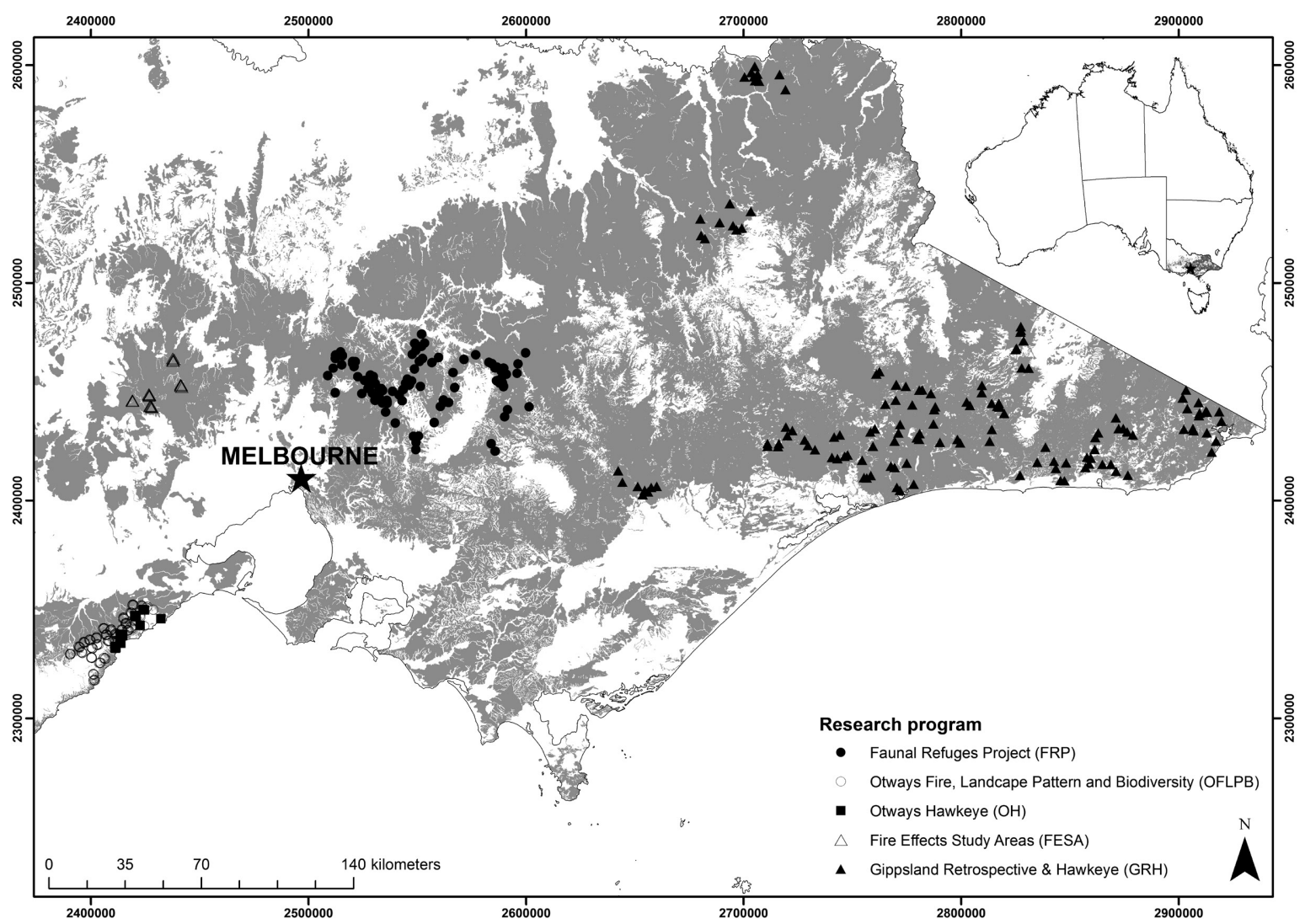

FIG. 1. Location of study sites within foothill forest vegetation (gray) in Victoria, Australia.

history of fire (Gill and Catling 2002), with current regimes characterised by wildfires, as well as prescribed burns undertaken for fuel reduction or ecological objectives (Gill 2009). Neither type of fire is stand-replacing in these forests because the dominant eucalypt species commonly survive fire and regenerate from epicormic shoots (Gill 1975). Nonetheless, there is much variation in the size and intensity of fires in foothill forests. Large (i.e., $>10,000 \mathrm{ha}$ ) and intense wildfires occur periodically, the most recent being the Black Saturday fires of 2009 that burnt around 100,000 ha of foothill forests (Cruz et al. 2012). Even within such intense wildfires, fire severity is variable (Leonard et al. 2014). Wildfires can also be of low intensity and small in size. Prescribed burns are commonly of lower intensity than wildfires, often being patchy burns that do not reach canopy strata (Cheal 2010). There are also seasonal differences in the occurrence of wildfires and prescribed fires; wildfires commonly occur in summer, whereas prescribed fires are typically undertaken in autumn or spring.

\section{Empirical datasets}

This study uses empirical data on vegetation structure collected by five different research programs: (1) the Faunal Refuges Project (FRP; 190 sites surveyed in
2010/2011); (2) the Otways Fire, Landscape Pattern and Biodiversity project (OFLPB; 129 sites surveyed in 2011/2012); (3) Otways HawkEye (OH; 23 sites surveyed in 2012); (4) the Fire Effects Study Areas (FESA; 25 sites surveyed in 2012); and (5) Gippsland Retrospective and HawkEye (GRH; 138 sites surveyed in 2011/2012). All programs were undertaken within large blocks of native forest vegetation and sought to select sites without recent (i.e., <30 yr) logging activity.

Data on vegetation structure were collected by three programs. At FRP sites, the number of vegetation contacts (live or dead) with a vertical ranging pole in five height-strata were recorded at $1-\mathrm{m}$ intervals on a $50-\mathrm{m}$ transect ( $n=50$ sample points per site). Identical information was recorded at 3 -m intervals on a $100-\mathrm{m}$ transect at OFLPB and OH sites ( $n=33$ sample points per site). Height strata were $0-0.5 \mathrm{~m}$ (ground), 0.5-1 m (low), 1-2 m (shrub), 2-4 m (sub-canopy), and $>4 \mathrm{~m}$ (canopy). The proportional cover of vegetation in each height stratum was calculated for each site. Using these data, the Shannon-Wiener diversity index $\left(\mathrm{H}^{\prime}\right)$ was also calculated to provide a measure of the structural diversity of vegetation.

All programs collected data on two key attributes of the ground cover at sites. Litter depth and the presence of bare ground were recorded at the sample points described 
above for FRP, OFLPB, and OH sites. At GRH sites, litter depth was recorded at the end of three 50-m transects, extending at bearings of $0^{\circ}, 120^{\circ}$, and $240^{\circ}$ from the center of sites ( $n=3$ sample points/site). At FESA sites, a grid of 5-10 $\mathrm{m}$ spacing was used to collect 15 litter depth measurements. The proportional cover of bare ground was calculated for FRP, OFLPB, and OH sites; mean litter depth, averaged across sample points, was calculated for all sites.

\section{Fire history and environmental attributes}

The fire history of sites was represented by four variables derived from fire-history mapping. Fire-history mapping has been undertaken by the Department of Environment, Land, Water and Planning (DELWP) and covers all fires since 1900, with the accuracy and resolution of mapping substantially increasing over time, notably >1970 (Department of Environment, Land, Water and Planning 2014). Time since fire (TSF) was calculated as the number of years between the year of the most recent fire and the year of the vegetation survey. Time since fire was able to be calculated more accurately using information on fire/survey month (in addition to year) for sites $5 \mathrm{yr}$ or younger since fire. The type of the most recent fire (wildfire or prescribed burn; Type) was used as a proxy for fire severity. Although varying in severity (Leonard et al. 2014), wildfires commonly are more intense than prescribed fires. Fire frequency (NumFires) was calculated as the number of fires occurring at sites between 1900 and time of vegetation assessment. Mean inter-fire interval (IFI) was calculated as the average number of years between successive fires at sites. IFI was calculated only for sites experiencing more than one fire. Sites with no mapped fire history were excluded from analyses.

To examine the effect of fire history over a shorter/ more recent period of time on vegetation structure, an alternate measure of NumFires was quantified to represent the number of fires occurring within $15 \mathrm{yr}$ of vegetation assessments at sites. Mapping of these recent fires is more reliable than earlier fires (e.g., <1970), and it was also considered possible that such fires will have a stronger effect on vegetation than older fires. Univariate generalized linear mixed models including the different versions of NumFires were compared for each response variable. In all cases, results showed both variables affected vegetation structure in a similar way. Akaike's information criterion (AIC; corrected for small sample sizes, $\mathrm{AIC}_{\mathrm{c}}$ ) was used to select the version of NumFires with greatest support, and results were equivocal (i.e., models had $\mathrm{AIC}_{\mathrm{c}}$ values within two points of each other; Burnham and Anderson 2002). Given similar conclusions, and the lack of consistently strong support for the variable calculated over the shorter period of time, NumFires quantified using the full fire history (described previously) was used in all analyses. Such comparisons were not possible for IFI due to the reduced dataset and
IFI range when this variable was calculated using only fires occurring within the last $15 \mathrm{yr}$.

Four variables were selected to represent key environmental characteristics of potential influence on vegetation structure. Mean rainfall in July (Rain, based on an ANUCLIM model applied to a digital elevation model; Houlder et al. 2003) was used to represent broad climatic patterns across the region. Finer-scale moisture availability was based on a digital elevation model which also incorporated some information on topography (Wetness; Schmidt and Persson 2003). A digital elevation model quantifying the proportion of sky visible from a given location was used to represent topographic position (Topo). Sites in gullies had less visible sky; those with more visible sky were located on slopes or ridges (Böhner and Antonic 2009). Broad vegetation type at a site was based on existing vegetation maps produced by DELWP (Department of Environment, Land, Water and Planning 2014), with the original classes combined into three categories on the basis of structural and environmental similarities: Driest (including Grassy/Heathy Dry Forest, Tall Mixed Forest), Dry (Foothills Forest, Forby Forest), and Mesic (Moist Forest, Riparian (or Higher Rainfall)).

\section{Data analyses}

Two types of mixed models were used to assess the relative influence of fire history ( $n=4$ variables) and environmental attributes $(n=4)$ on vegetation structure (the response variables, $n=8$ ). First, generalized additive mixed models (GAMMs) were used to identify non-linear relationships between predictor and response variables. If non-linearity was detected using exploratory GAMMs, then predictor variables were transformed prior to further analyses. Transformations included natural logarithm and 1/natural logarithm (see Fig. 2). Second, all predictor variables (transformed if necessary, based on GAMM results) were included in a single additive (i.e., no interaction terms) global generalized linear mixed model (GLMM). Standardized parameter estimates, and associated standard errors, were used to compare effect sizes between predictor variables.

To assess whether post-fire change in vegetation structure is influenced by other fire regime attributes, GLMMs with and without selected interaction terms were compared for each response variable. Such comparisons were undertaken for interactions between TSF (representing post-fire change) and all other fire history attributes (Type, NumFires, IFI). AIC $_{\mathrm{c}}$ values were used to assess the strength of support for interaction terms. Strong support was identified when the $\mathrm{AIC}_{\mathrm{c}}$ value of the model with the interaction term was more than two points lower than the model without the interaction term (Burnham and Anderson 2002).

The same approach was taken when determining whether fire severity alters the effect of preceding fires on vegetation structure. Here, GLMMs with and without interaction terms between Type (representing fire 

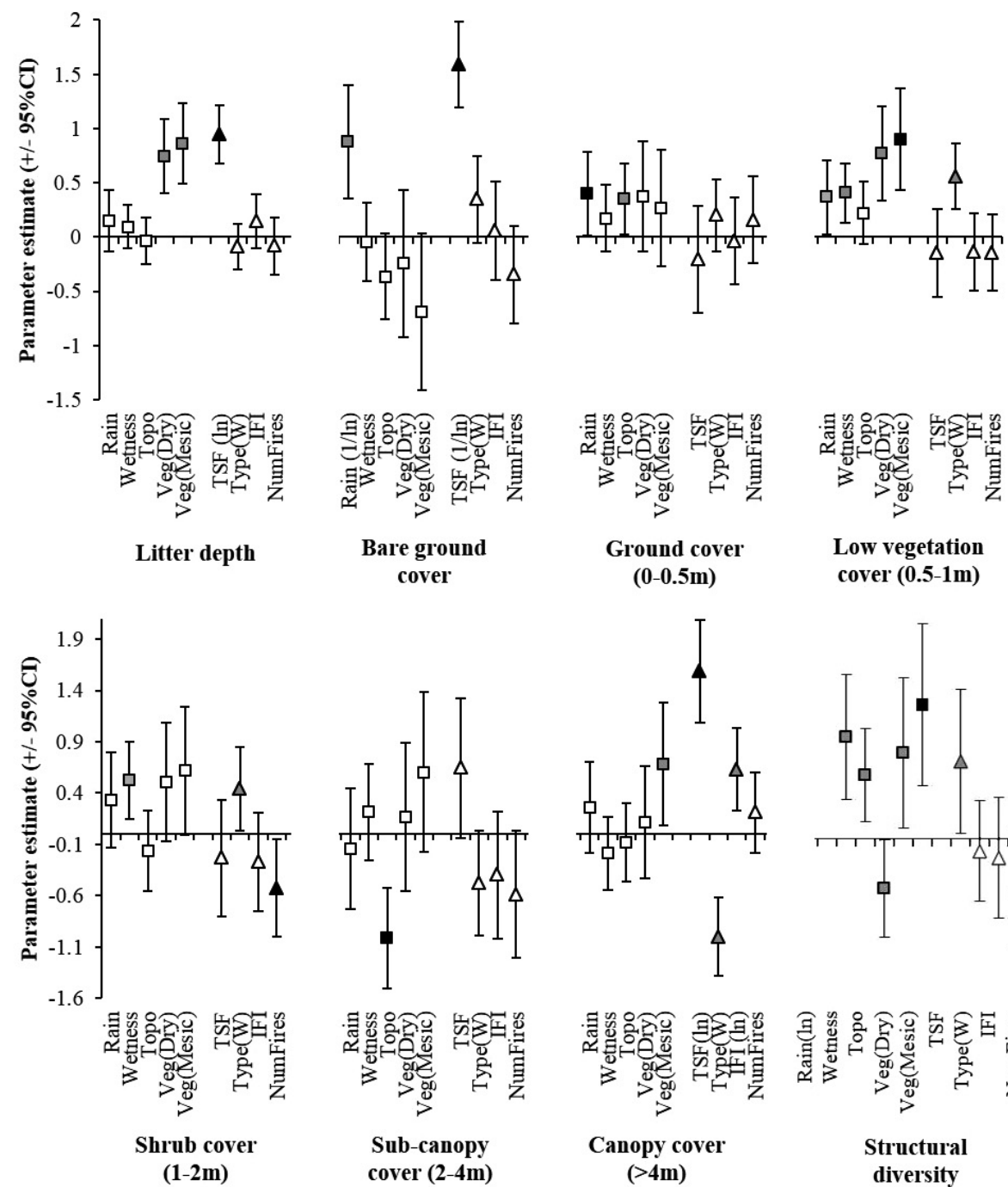

Bare ground
cover

\section{Ground cover (0-0.5m)}

Low vegetation cover (0.5-1m)
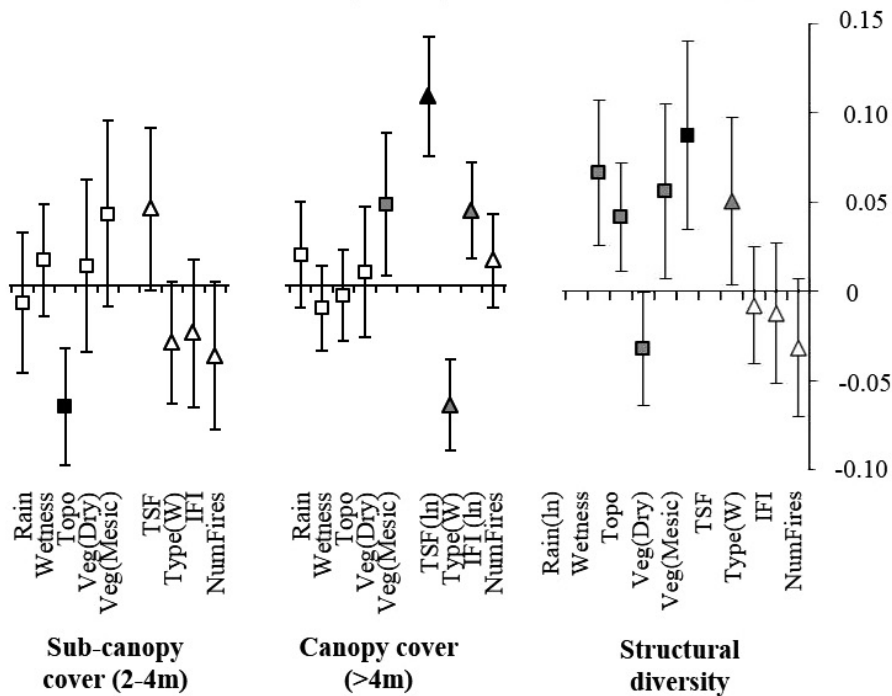

FIG. 2. Parameter estimates ( $₫ 95 \%$ confidence intervals) from generalized linear mixed models for the relationship between environmental (squares) and fire history (triangles) drivers and different attributes of vegetation structure. Solid symbols indicate parameter estimates for which the $95 \%$ confidence intervals do not include zero, with black indicating the variable with the largest parameter estimate (i.e., strongest effect on associated response variable).

severity) and attributes of preceding fire history (NumFires, IFI) were compared. To ensure results were not influenced by systematic variation in the fire-age of sites, TSF was also included in these models for response variables that showed a strong relationship with TSF in global models. $\mathrm{AIC}_{\mathrm{c}}$ values were again used to determine whether fire type overrides the effect of preceding fires on vegetation structure (i.e., by identifying strong support for the model with the interaction term).

Environmental variables were included in all interaction models to ensure comparisons accounted for the effect of these potentially influential attributes. In addition, datasets were limited to ensure equivalent ranges of predictor variables across interacting variables, so that results were not influenced by the spread/values of interacting variables (box/bar plots of interacting variables are included in Appendix S1: Fig. S1). In datasets with fewer than four mapped fires (e.g., NumFires <4), NumFires was modelled as a categorical term with each value being a different category. Similarly, IFI was included as a categorical term with two levels (e.g., short mean IFI/long mean IFI; see Appendix S5: Table S1 and Appendix S7: Table S1 for details) in interaction models.

Predictor variables were standardized prior to analysis and assessed for collinearity (all $r<0.7$, the level at which collinearity can seriously affect model results; Dormann et al. 2013). Measures of inter-fire interval and fire frequency are often highly, sometimes completely, collinear. Here, the correlation between IFI and NumFires was reduced because of the extended period of fire history 
over which these variables were calculated (i.e., >100 yr). In our datasets, for example, for sites with two fires these occurred between 1 and $72 \mathrm{yr}$ apart, while the mean interval between fires for sites affected by three fires ranged between 5 and $36 \mathrm{yr}$.

All models were fitted with a random term representing geographic region to account for non-independence due to broad spatial patterns, as well as differences in field methods between programs (different programs were generally undertaken in different regions). Response variables representing the proportional cover of vegetation in different height strata were modelled using a binomial error distribution; these models included an additional observation-level random term to account for overdispersion (Zuur et al. 2012). Litter depth and structural diversity were modelled using a Gaussian error distribution. All analyses were undertaken in $\mathrm{R}$ v.3.0.2 ( $\mathrm{R}$ Development Core Team 2013) using the following packages: lme4 v.1.0-4 (Bates et al. 2013), mgcv v.1.7-24 (Wood 2011), MuMIn v.1.9.13 (Barton 2013), and AICcmodavg v.1.31 (Mazerolle 2013).

\section{RESUlTS}

Results of global models showed that both fire and environmental drivers affect vegetation structure in foothill forests (Fig. 2). Fire history attributes were the strongest driver of litter depth, the proportional cover of bare ground, and shrub (1-2 m) and canopy (>4 m) strata. Litter depth and canopy cover increased with time since fire; the cover of bare ground decreased (the transformation of TSF [1/ln] in the bare ground model reflects a negative relationship, despite the positive parameter estimate in Fig. 2). Shrub (1-2 m) cover decreased with fire frequency. Additional fire effects were also identified. Fire type affected the cover of low $(0.5-1 \mathrm{~m})$, shrub (1-2 m), and canopy (>4 m) vegetation; wildfire led to greater cover of low and shrub vegetation, and less canopy cover, relative to prescribed fire. Canopy cover increased with IFI, and structural diversity increased with TSF (Fig. 2). Appendix S2: Fig. S1 includes prediction plots of these relationships.
Environmental drivers had the strongest influence on vegetation cover in ground $(0-0.5 \mathrm{~m})$, low $(0.5-1 \mathrm{~m})$, and sub-canopy (2-4 m) strata, as well as overall structural diversity. All response variables were influenced by at least one environmental variable, with Rain and vegetation type having a strong effect in most models. In both cases, relationships with these variables were consistently positive, indicating that vegetation is denser (in associated strata) and more structurally diverse in areas of higher mean rainfall, and in Mesic and/or Dry vegetation types relative to the Driest vegetation type (Fig. 2).

Variables representing fire and environmental attributes accounted for a relatively limited amount of variation in response variables. The highest marginal $R^{2}$ value (representing the influence of fixed effects only) for any global model was $16 \%$ (Table 1 ). Conditional $R^{2}$ values (representing both fixed and random terms) were often markedly higher, explaining $28-60 \%$ of variation in the data. Appendix S3: Table S1 and Appendix S4: Fig. $\mathrm{S} 1$ provide details of the predictor variables included in global models.

There was clear support for an interaction between post-fire change (TSF) and fire severity (Type) for canopy (>4 m) cover (Appendix S5: Table S1). Canopy cover increased with time since wildfire but showed no discernible change with time since prescribed burn (Fig. 3). The $\mathrm{AIC}_{\mathrm{c}}$ values of comparison models also indicated support for an interaction between TSF and IFI for shrub (1-2 m) cover and structural diversity (Appendix S5: Table S1). However, prediction plots from the interaction models revealed that time-since-fire relationships for these variables were very similar for sites with short and with long inter-fire intervals (Appendix S6: Fig. S1). Thus, these interactions are not considered ecologically meaningful.

The severity of the most recent fire (Type) did not alter the effect of preceding fires (NumFires, IFI) on any attribute of vegetation structure examined (Appendix S7: Table S1). However, our capacity to examine this question adequately was limited because NumFires and IFI did not have a strong effect in any model; measures of preceding fires must affect vegetation structure for

TABLE 1. Number of sites included in generalized linear mixed models relating attributes of vegetation structure to fire and environmental drivers, and an estimate of how much variation models explain.

\begin{tabular}{lccr}
\hline \hline Vegetation attribute & Number sites (regions) & Marginal $R^{2}(\%)$ & Conditional $R^{2}(\%)$ \\
\hline Litter depth (sqrt) $\dagger$ & $378(5)$ & 15.8 & 66.2 \\
Bare ground cover $\$$ & $276(2)$ & 10.6 & 44.8 \\
Ground cover $(0-0.5 \mathrm{~m})+$ & $276(2)$ & 2.2 & 37.3 \\
Low vegetation cover $(0.5-1 \mathrm{~m})+$ & $276(2)$ & 5.6 & 28.1 \\
Shrub cover $(1-2 \mathrm{~m})+$ & $276(2)$ & 5.0 & 43.4 \\
Sub-canopy cover $(2-4 \mathrm{~m})+$ & $276(2)$ & 12.3 & 50.3 \\
Canopy cover $(>4 \mathrm{~m})+$ & $276(2)$ & 16.0 & 43.1 \\
Structural diversity $\dagger$ & $276(2)$ & 50.4 \\
\hline
\end{tabular}

Notes: Marginal $R^{2}$ values indicate variation explained by the fixed effects in models (i.e., fire and environmental drivers); conditional $R^{2}$ values indicate variation explained by fixed and random effects.

$\dagger$ Random effect is region.

$\$$ Random effects are region and observation-level term. 


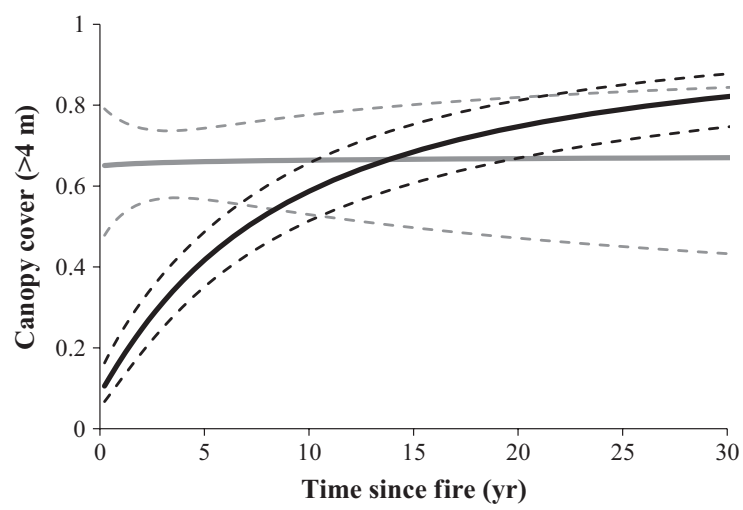

FIG. 3. Predicted time-since-fire relationships for canopy cover $(>4 \mathrm{~m})$ following fires of high severity (black, wildfire) and low severity (gray, prescribed burn). Predicted values are plotted for Dry vegetation; dashed lines show the $95 \%$ confidence intervals of predictions.

their effects to be altered by fire type. The only exception to this was the negative relationship between NumFires and canopy ( $>4 \mathrm{~m}$ ) cover identified in the additive model (i.e., no interaction term; Appendix S7: Table S1). This finding shows that the type of the most recent fire did not override the (negative) effect of NumFires on canopy cover.

\section{DisCUSSION}

The structure of foothill forest vegetation is influenced by both fire history and environmental characteristics, with the relative strength of these drivers differing between structural attributes. Fire exerted the strongest influence on half of the measures of vegetation structure we examined; environmental factors had the strongest effect on the other half. However, while all vegetation measures were affected to some extent by environmental variables, two of eight did not respond to fire history. Understanding whether forest structure is driven by processes amenable to management (e.g., fire) or factors outside of human control (e.g., environmental gradients) is informative, particularly in systems where processes such as fire are actively managed to achieve specific goals. Our results highlight that in foothill forests, where prescribed burns are regularly applied, fire is only one of many processes to shape forest structure. This has implications for the use of prescribed burns as a management tool to alter vegetation structure/fuel availability. Some fuel types (e.g., "elevated" fuels $<4 \mathrm{~m}$ ) are influenced primarily by environmental gradients and will show a weaker response to the effects of prescribed burns.

Time since fire was of particular importance in influencing the structure of foothill forests. In addition, the severity of the most recent fire (represented by fire type) affected the cover of vegetation in some strata. These findings add to the body of research identifying that fire has important effects in temperate eucalypt forests (e.g.,
Gill 1975, Collins et al. 2012, Aponte et al. 2014, Sitters et al. 2014), with potential flow-on effects for other attributes of the biota (e.g., York 1999, Nugent et al. 2014). In our analyses, time since fire and fire type both represented attributes of the most recent fire. In contrast, it was less common for measures of preceding fires (NumFires, IFI) to have a strong effect on vegetation structure. This differs from some other forested systems where fire frequency has a strong effect on vegetation structure (Spencer and Baxter 2006, Collins et al. 2012). Our contrasting results are likely to be related to differences in fire history characteristics (e.g., Spencer and Baxter 2006; sampled sites burnt more frequently and at shorter intervals than ours) or the spatial extent of investigation (e.g., Collins et al. 2012; see below).

Previous work in this system has shown that repeated prescribed burns over a 27-yr period substantially reduced coarse woody debris, an important habitat resource in foothill forests (Aponte et al. 2014). Thus, while current results suggest that measures of vegetation structure are most strongly influenced by characteristics of the most recent fire, the availability of individual habitat features that provide key resources for fauna (e.g., large logs, hollow-bearing trees) must also be considered, and these may be strongly influenced by fire frequency and interval (Banks et al. 2011, Aponte et al. 2014). Fire regimes characterized by different sequences of past fires (e.g., more frequent and/or severe fires, shorter inter-fire intervals) may also have a stronger effect on vegetation structure. For example, repeated severe wildfires within a short ( $\sim 10$ years) period of time in foothill forest can result in the loss of canopy eucalypts (M. Clarke, personal observation), thus substantially altering vegetation structure.

The impact of fire on vegetation structural features has ramifications for other components of biodiversity in foothill forests. The strong effect of time since fire on ground and canopy layers has implications for the suitability of habitat for associated fauna. For example, increased abundances of both ground- and canopyforaging bird species in unburnt patches of foothill forest, relative to surrounding recently burnt vegetation, is likely related to the food resources provided by older habitat (Robinson et al. 2014). Our results show older vegetation has deeper leaf litter (and less open ground), more welldeveloped canopy layers, and greater structural diversity. Such features are likely to result in greater diversity/ abundance of invertebrates, flowering/fruiting plants, and foraging substrates. Similarly, fire severity influences the occurrence of the superb lyrebird Menura novaehollandiae via effects on low and shrub vegetation. The dense cover of regenerating vegetation $<2 \mathrm{~m}$ promoted by severe wildfire provides unsuitable foraging habitat, whereas superb lyrebirds do forage in more open vegetation resulting from less intense fires (Nugent et al. 2014). The value of insights provided by fire-vegetation relationships for understanding and predicting how fire will affect animal species has been emphasized by 
previous work in this (Sitters et al. 2014) and other (Parr et al. 2004) fire-prone systems.

A key objective of this study was to examine the potential interaction between characteristics of the most recent fire event and other attributes of fire regimes, in terms of their effects on vegetation structure. There was some evidence of support for our first hypothesis: post-fire succession is influenced by measures of the fire regime other than time since fire. Our results showed that the type/severity of the most recent fire influenced post-fire canopy regeneration. Prescribed/low severity burns in foothill forests rarely affect canopy strata while more severe wildfires regularly remove canopy vegetation, which then regenerates from surviving live trees (Cheal 2010). Thus, this result is related to the different starting points in canopy cover that result from low and high severity fires. This highlights the importance of ensuring equivalent baseline (time-zero) states across replicates; a critical consideration for fire research employing a chronosequence approach (Turner et al. 1998, Gill and Catling 2002). Importantly here, attributes of past fires, rather than environmental characteristics (e.g., Nimmo et al. 2014, Brown et al. 2015), determined successional pathways. Previous work has similarly identified an effect of fire severity on post-fire succession in forest vegetation (Ashton and Martin 1996, Díaz-Delgado et al. 2003, Kuenzi et al. 2008, Shive et al. 2013), with the strength of such interactions in coniferous forests indicating that multiple successional pathways are required to understand long-term change after fire (Lecomte et al. 2006).

There was limited capacity to examine our second hypothesis, that the type/severity of the most recent fire overrides the influence of preceding fires, due to minimal effects of preceding fires on vegetation structure. Nonetheless, the influence of fire frequency (NumFires) on canopy cover was not found to be overridden by the type of the most recent fire; canopy cover decreased with the number of past fires at sites. These findings highlight that even though attributes of individual fire events appear to have the dominant effect on vegetation structure in this system, the potential influence of other aspects of fire regimes cannot be dismissed. Further evidence for this comes from Aponte et al. (2014), who detected an effect of fire frequency on logs in foothill forests. The degree to which fire severity alters the influence of preceding fires may also be contingent on environmental conditions. For example, in the current study region, Bassett et al. (2015) found that severe wildfires obscured the effect of preceding fires (in this case, previous time since fire of burnt vegetation) on logs and dead trees on slopes but not in gullies.

These findings must be considered in light of two important factors. First, fires in foothill forests are not stand-replacing; canopy species survive even severe individual wildfires and regenerate post-fire from epicormic buds (Gill 1975). This contrasts with some other fireprone systems, including parts of the boreal forests
(Lecomte et al. 2006) and semi-arid mallee vegetation (Haslem et al. 2011), where fires commonly reset successional pathways. The retention of key forest attributes such as canopy trees, which represent important biological legacies (Foster et al. 1998), may reduce the likelihood of detecting a strong fire-related signature on vegetation structure. However, the timeframe over which fire responses are considered may be influential: long-term changes to fire regimes have resulted in marked changes to the structure of forests dominated by ponderosa pine Pinus ponderosa var. scopulorum, a species known to survive surface fires, in parts of the USA (Brown 2006). Nonetheless, variation in the magnitude of changes to vegetation structure following fire has flow-on effects for the degree to which associated faunal species are resilient to fire (Barrow et al. 2007).

Second, empirical data employed in these analyses were collected over a large geographic area. Consequently, it is to be expected that broad environmental gradients, notably annual rainfall and vegetation type, will influence patterns of vegetation structure across sites. Other research into fire-vegetation relationships across large areas has similarly identified an overriding effect of broad-scale geographic gradients (Turner et al. 1997). The importance of considering environmental drivers in fire-prone systems is further emphasized by work in tall wet forests: abiotic factors such as topography exerted a substantial influence on bird occurrence following a large, stand-replacing wildfire, despite major changes to vegetation structure (Lindenmayer et al. 2014).

\section{CONCLUSION}

Fire history attributes had complex effects on the structure of foothill forest vegetation. Ground vegetation $(0-0.5 \mathrm{~m})$ and sub-canopy $(2-4 \mathrm{~m})$ cover were not affected by fire history whereas other strata, notably ground cover and canopy layers, showed stronger relationships with fire history measures. Particularly important were attributes of the most recent fire, both its type/severity and the length of time since its occurrence. Other attributes of fire regimes (inter-fire interval, fire frequency) exerted lesser influence on vegetation structure. While the relatively weak effects of fire on some vegetation attributes may be related to the characteristics of fire in this system, or the large study area, they indicate that at broad scales, structural attributes of foothill forest vegetation appear relatively resilient to the effects of current fire regimes. However, fire management for hazard reduction may result in more extreme fire regimes than examined here (notably higher fire frequencies, shorter inter-fire intervals), and such conditions are likely to have more marked effects on foothill forest vegetation. Further work is required to determine whether these results are observed at the more localized scales at which fire management is often undertaken, and the ramifications of fire-related vegetation change for other components of the biota of foothill forests, notably fauna. 


\section{ACKNOWLEDGMENTS}

We appreciate the efforts of many people involved in the five research programs which contributed data to these analyses: the Faunal Refuges Project; the Otways Fire, Landscape Pattern and Biodiversity project; Otways HawkEye; the Fire Effects Study Areas; and Gippsland Retrospective and HawkEye. We thank other members of the Foothills Fire and Biota Project team for their contributions to this work: Julian Di Stefano, Richard Loyn, Kasey Stamation, and Libby Rumpff. Funding for this project has been received from the Bushfire and Natural Hazards Cooperative Research Centre and the Department of Environment, Land, Water and Planning. We thank a reviewer for thoughtful comments that improved previous versions of this manuscript.

\section{Literature Cited}

Aponte, C., K. G. Tolhurst, and L. T. Bennett. 2014. Repeated prescribed fires decrease stocks and change attributes of coarse woody debris in a temperate eucalypt forest. Ecological Applications 24:976-989.

Ashton, D., and D. Martin. 1996. Regeneration in a pole-stage forest of Eucalyptus regnans subjected to different fire intensities in 1982. Australian Journal of Botany 44:393-410.

Banks, S. C., E. J. Knight, L. McBurney, D. Blair, and D. B. Lindenmayer. 2011. The effects of wildfire on mortality and resources for an arboreal marsupial: resilience to fire events but susceptibility to fire regime change. PLoS ONE 6:e22952.

Barrow, L., C. L. Parr, and J. L. Kohen. 2007. Habitat type influences fire resilience of ant assemblages in the semi-arid tropics of Northern Australia. Journal of Arid Environments 69:80-95.

Barton, K. 2013. MuMIn: Multi-model inference. Version 1.9.13. http://CRAN.R-project.org/package $=$ MuMIn

Bassett, M., E. K. Chia, S. W. J. Leonard, D. G. Nimmo, G. J. Holland, E. G. Ritchie, M. F. Clarke, and A. F. Bennett. 2015. The effects of topographic variation and the fire regime on coarse woody debris: insights from a large wildfire. Forest Ecology and Management 340:126-134.

Bates, D., M. Maechler, B. Bolker, and S. Walker. 2013. lme4: linear mixed-effects models using Eigen and S4. Version 1.04. http://CRAN.R-project.org/package $=1 \mathrm{me} 4$

Beaty, R. M., and A. H. Taylor. 2008. Fire history and the structure and dynamics of a mixed conifer forest landscape in the northern Sierra Nevada, Lake Tahoe Basin, California, USA. Forest Ecology and Management 255:707-719.

Böhner, J., and O. Antonic. 2009. Land-surface parameters specific to topo-climatology. Developments in Soil Science 33:195-226.

Bowman, D., et al. 2009. Fire in the Earth system. Science 324:481-484.

Brown, P. M. 2006. Climate effects on fire regimes and tree recruitment in Black Hills ponderosa pine forests. Ecology $87: 2500-2510$.

Brown, C. D., J. Liu, G. Yan, and J. F. Johnstone. 2015. Disentangling legacy effects from environmental filters of post-fire assembly of boreal tree assemblages. Ecology 96:3023-3032.

Burnham, K. P., and D. R. Anderson. 2002. Model selection and multimodel inference: a practical information-theoretic approach. Springer, New York, New York, USA.

Capitanio, R., and C. Carcaillet. 2008. Post-fire Mediterranean vegetation dynamics and diversity: a discussion of succession models. Forest Ecology and Management 255:431-439.

Catling, P. 1991. Ecological effects of prescribed burning practices on the mammals of southeastern Australia. Pages 353-363 in D. Lunney, editor. Conservation of Australia's forest fauna. Royal Zoological Society of NSW, Mosman, New South Wales, Australia.

Cheal, D. C. 2010. Growth stages and tolerable fire intervals for Victoria's native vegetation data sets. Fire and Adaptive Management Report No. 84. Department of Sustainability and Environment, East Melbourne, Victoria, Australia.

Collins, L., R. A. Bradstock, E. M. Tasker, and R. J. Whelan. 2012. Can gullies preserve complex forest structure in frequently burnt landscapes? Biological Conservation 153: 177-186.

Conn, B. 1993. Natural regions and vegetation of Victoria. Pages 79-158 in D. B. Foreman and N. G. Walsh, editors. Flora of Victoria. Inkata Press, Melbourne, Victoria, Australia.

Cruz, M. G., A. L. Sullivan, J. S. Gould, N. C. Sims, A. J. Bannister, J. J. Hollis, and R. J. Hurley. 2012. Anatomy of a catastrophic wildfire: the Black Saturday Kilmore East fire in Victoria, Australia. Forest Ecology and Management 284:269-285.

Department of Environment, Land, Water and Planning. 2014. Victorian corporate spatial data layer. Department of Land, Environment, Water and Planning, Victoria, Australia.

Díaz-Delgado, R., F. Lloret, and X. Pons. 2003. Influence of fire severity on plant regeneration by means of remote sensing imagery. International Journal of Remote Sensing 24: $1751-1763$.

Doherty, T. S., R. A. Davis, and E. J. B. Van Etten. 2015. A game of cat-and-mouse: microhabitat influences rodent foraging in recently burnt but not long unburnt shrublands. Journal of Mammalogy 96:324-331.

Dormann, C. F., et al. 2013. Collinearity: a review of methods to deal with it and a simulation study evaluating their performance. Ecography 36:027-046.

Fernandes, P. M., and H. S. Botelho. 2003. A review of prescribed burning effectiveness in fire hazard reduction. International Journal of Wildland Fire 12:117-128.

Ferran, A., and V. R. Vallejo. 1992. Litter dynamics in post-fire successional forests of Quercus ilex. Vegetatio 99:239-246.

Fisher, J. L., W. A. Loneragan, K. Dixon, J. Delaney, and E. J. Veneklaas. 2009. Altered vegetation structure and composition linked to fire frequency and plant invasion in a biodiverse woodland. Biological Conservation 142:2270-2281.

Foster, D. R., D. H. Knight, and J. F. Franklin. 1998. Landscape patterns and legacies resulting from large, infrequent forest disturbances. Ecosystems 1:497-510.

Fox, B. J. 1982. Fire and mammalian secondary succession in an Australian coastal heath. Ecology 63:1332-1341.

Gill, A. M. 1975. Fire and the Australian flora: a review. Australian Forestry 38:4-25.

Gill, A. M. 2009. Underpinnings of fire management for biodiversity conservation in reserves. Victorian Government Department of Sustainability and Environment, Melbourne, Victoria, Australia.

Gill, A. M., and P. C. Catling. 2002. Fire regimes and biodiversity of forested landscapes of southern Australia. Pages 351-369 in R. Bradstock, J. E. Williams, and A. M. Gill, editors. Flammable Australia: the fire regimes and biodiversity of a continent. Cambridge University Press, Cambridge, UK.

Gill, A., R. Bradstock, and J. Williams. 2002. Fire regimes and biodiversity: legacy and vision. Pages 429-446 in $\mathrm{R}$. Bradstock, J. E. Williams, and A. M. Gill, editors. Flammable Australia: the fire regimes and biodiversity of a continent. Cambridge University Press, Cambridge, UK.

Haslem, A., et al. 2011. Habitat or fuel? Implications of longterm, post-fire dynamics for the development of key resources for fauna and fire. Journal of Applied Ecology 48:247-256.

Houlder, D., M. Hutchinson, H. Nix, and J. McMahon. 2003. ANUCLIM 5.1 user's guide. Centre for Resource and 
Environmental Studies, The Australian National University, Canberra, Australian Capital Territory, Australia.

Hutto, R. L. 2008. The ecological importance of severe wildfires: some like it hot. Ecological Applications 18:1827-1834.

Kelly, L. T., D. G. Nimmo, L. M. Spence-Bailey, A. Haslem, S. J. Watson, M. F. Clarke, and A. F. Bennett. 2011. Influence of fire history on small mammal distributions: insights from a 100-year post-fire chronosequence. Diversity and Distributions 17:462-473.

Kodandapani, N., M. A. Cochrane, and R. Sukumar. 2004. Conservation threat of increasing fire frequencies in the Western Ghats, India. Conservation Biology 18:1553-1561.

Kuenzi, A. M., P. Z. Fulé, and C. H. Sieg. 2008. Effects of fire severity and pre-fire stand treatment on plant community recovery after a large wildfire. Forest Ecology and Management 255:855-865.

Lecomte, N., M. Simard, N. Fenton, and Y. Bergeron. 2006. Fire severity and long-term ecosystem biomass dynamics in coniferous boreal forests of eastern Canada. Ecosystems 9:1215-1230.

Leonard, S. W. J., A. F. Bennett, and M. F. Clarke. 2014. Determinants of the occurrence of unburnt forest patches: potential biotic refuges within a large, intense wildfire in south-eastern Australia. Forest Ecology and Management 314:85-93.

Lindenmayer, D. B., J. T. Wood, R. B. Cunningham, C. MacGregor, M. Crane, D. Michael, R. Montague-Drake, D. Brown, R. Muntz, and A. M. Gill. 2008. Testing hypotheses associated with bird responses to wildfire. Ecological Applications 18:1967-1983.

Lindenmayer, D. B., W. Blanchard, L. McBurney, D. Blair, S. C. Banks, D. A. Driscoll, A. L. Smith, and A. M. Gill. 2014. Complex responses of birds to landscape-level fire extent, fire severity and environmental drivers. Diversity and Distributions 20:467-477.

Lutze, M. T., R. G. Campbell, and P. C. Fagg. 1999. Development of silviculture in the native state forests of Victoria. Australian Forestry 62:236-244.

Mazerolle, M. J. 2013. AICcmodavg: model selection and multimodel inference based on (Q)AIC(c). Version 1.31. http:// CRAN.R-project.org/package=AICcmodavg

Motzkin, G., P. Wilson, D. R. Foster, and A. Allen. 1999. Vegetation patterns in heterogeneous landscapes: the importance of history and environment. Journal of Vegetation Science 10:903-920.

Nimmo, D., L. Kelly, L. Farnsworth, S. Watson, and A. Bennett. 2014. Why do some species have geographically varying responses to fire history? Ecography 37:805-813.

Noble, I. R., and R. O. Slatyer. 1980. The use of vital attributes to predict successional changes in plant communities subject to recurrent disturbances. Vegetatio 43:5-21.

Nugent, D. T., S. W. Leonard, and M. F. Clarke. 2014. Interactions between the superb lyrebird (Menura novaehollandiae) and fire in south-eastern Australia. Wildlife Research 41:203-211.

Parker, K. C. 1991. Topography, substrate, and vegetation patterns in the northern Sonoran Desert. Journal of Biogeography 18:151-163.
Parr, C. L., H. G. Robertson, H. C. Biggs, and S. L. Chown. 2004. Response of African savanna ants to long-term fire regimes. Journal of Applied Ecology 41:630-642.

Pons, P., and R. Prodon. 1996. Short term temporal patterns in a Mediterranean shrubland bird community after wildfire. Acta Oecologica 17:29-41.

R Development Core Team. 2013. R: a language and environment for statistical computing. 2.15.3. R Foundation for Statistical Computing, Vienna, Austria. https://www.R-project.org/

Robinson, N. M., S. W. Leonard, A. F. Bennett, and M. F. Clarke. 2014. Refuges for birds in fire-prone landscapes: the influence of fire severity and fire history on the distribution of forest birds. Forest Ecology and Management 318:110-121.

Schmidt, F., and A. Persson. 2003. Comparison of DEM data capture and topographic wetness indices. Precision Agriculture 4:179-192.

Shive, K. L., C. H. Sieg, and P. Z. Fulé. 2013. Pre-wildfire management treatments interact with fire severity to have lasting effects on post-wildfire vegetation response. Forest Ecology and Management 297:75-83.

Sitters, H., F. Christie, J. Di Stefano, M. Swan, P. Collins, and A. York. 2014. Associations between occupancy and habitat structure can predict avian responses to disturbance: implications for conservation management. Forest Ecology and Management 331:227-236.

Smucker, K. M., R. L. Hutto, and B. M. Steele. 2005. Changes in bird abundance after wildfire: importance of fire severity and time since fire. Ecological Applications 15:1535-1549.

Spencer, R. J., and G. S. Baxter. 2006. Effects of fire on the structure and composition of open eucalypt forests. Austral Ecology 31:638-646.

Turner, M. G., W. H. Romme, R. H. Gardner, and W. W. Hargrove. 1997. Effects of fire size and pattern on early succession in Yellowstone National Park. Ecological Monographs 67:411-433.

Turner, M. G., W. L. Baker, C. J. Peterson, and R. K. Peet. 1998. Factors influencing succession: lessons from large, infrequent natural disturbances. Ecosystems 1:511-523.

Williams, R. J., G. A. Duff, D. M. J. S. Bowman, and G. D. Cook. 1996. Variation in the composition and structure of tropical savannas as a function of rainfall and soil texture along a large-scale climatic gradient in the Northern Territory, Australia. Journal of Biogeography 23:747-756.

Wood, S. N. 2011. Fast stable restricted maximum likelihood and marginal likelihood estimation of semiparametric generalized linear models. Journal of the Royal Statistical Society B 73:3-36.

York, A. 1999. Long-term effects of frequent low-intensity burning on the abundance of litter-dwelling invertebrates in coastal blackbutt forests of southeastern Australia. Journal of Insect Conservation 3:191-199.

Zedler, P. H., C. R. Gautier, and G. S. McMaster. 1983. Vegetation change in response to extreme events: the effect of a short interval between fires in California chaparral and coastal scrub. Ecology 64:809-818.

Zuur, A. F., A. A. Saveliev, and E. N. Ieno. 2012. Zero inflated models and generalized linear mixed models with R. Highland Statistics, Newburgh, UK.

\section{SUPPORTING INFORMATION}

